\title{
A Sociology of Trust
}

\author{
Jason L. Powell \\ Faculty of Health \& Life Sciences, Coventry University, Priory Street, CV1 5FB, \\ Coventry, United Kingdom
}

E-mail address: jasonpwll3@gmail.com

\section{ABSTRACT}

The paper is a critical review of the problems and implications of tru in the British community care system. It is a system in need of strong di of the world economic downturn in recent years. Despite raft of poli the UK, the structural issues for why the needs of diverse groups a no the diffy ar to understand at particular levels of analysis. The central problem has been co 'tru The paper detangles the implications of different forms of trust in order to understan carorelations.

Keywords: trust; sociology; leadership; care and structur

\section{INTRODUCTION}

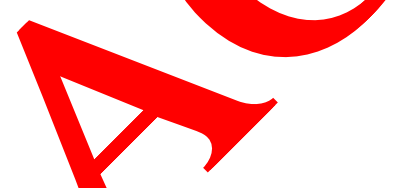

Trust is fraught with a mul plic of prob $\mathrm{ms}$ in the UK. For example, community care legislation has in the past dece ecei ed scanti y uncritical sociological acclaim. Community care policy based on the tri vira caum my', 'empowerment' and 'choice' was endorsed by many commentators the polit and philosophical panacea for alleviating the deep and destructive problems on the munity care system in the UK (Powell, 2009). This paper deconstruct he ha $\hat{a}_{\text {t }}$ oraphy surrounding community care policy. The broken relationship bet veen profession and older people has been placated on distrust. A close and cogent exan ation the emergence of community care policy in the UK raises serious questions abo main tentions. Whose account was to count in the formulation and implem tion o amm anity care policy was based on a hierarchical vision of care truth in whi n the finition reality articulated by older people was secondary to reality defined by "exp 's/s such as policy advisors. In other words, it is "expert" led with no unders fing or diversity and experiences of users.

Th. maybe not the place to explore the epistemological and ontological debates concerning definitions of reality that have developed in social gerontology in recent years (Biggs and Powell 2000). However, it is important to note that community care policy fails to convey in any strong sense alternative definitions of truth or different visions of care truth based on older people's subjective experiences (Biggs and Powell 2000). Rather, the agism of community care policy has perpetually directed its gaze downwards towards older people thus reinforcing 'an overall impression that these are the people who need to be researched, these are the ones who are out of step with 'social norms' or who are causing the problems' (Smart 1984: 150-1). Conversely, community care policy rarely gazes upwards to look at 'the locally 
powerful' (Smart: 1984) who in the case of older people would be care managers. The lack of any critical analysis of the role and daily practices of care managers constitutes a major weakness of the implementative process of the policy process in the UK in terms of accountability and sensitisation of diversity in managerial philosophy and practice.

The confusion and conflict between different state servants over the past 20 years provide clear illustrations of the fractured dislocation within the state concerning community care policy and muddled issues relating to managing diversity. However, it also leads the space, whether imaginative or experiential, by which care managers and older people interact. It is within that space that an understanding of 'trust' is the missing cement to bind relationships boeed on managing diversity. 'Trust' itself is an essentially contested concept. Trust can ext id to pu with a sense of shared identity (Gilson 2003, Tulloch and Lupton 2003). Indi "uals produ trust through experience and over time. It cannot be immediately and with pyroos oroduc by organizations or governments without dialogical interaction with peore on issuc rect $\mathrm{ng}$ their lifestyles and life-chances such as care, pensions, employment an colitic repres cation (Walker and Naeghele, 1999).

Möllering (2001) takes the relational theme further by dinguish betw en trust in contracts between individuals and the State in areas sucb a ension p sion; trust in friendships across intergenerational lines; trust in love apd elatio ips, and trust in foreign issues associated with national identity. There is a m itup ity of thas has been defined but the central paradox is how to creation of the conditions of ouilding conditions of trust across personal-organisational-structural tiers an increa ngly uncertain world. The chapter explores community care policy and navig the way, trust relations can capture stronger bonds and relationships between care manage or groups such as older people in the UK.

\section{COMMUNITY CARE IN TAE : CON EXXTUL BACKDROP}

Contemporary comm significant factors during the dominance of the Cons ative adm tration in the UK from 1979 onwards and has seen a resurgence in 2010 w in "financia reforms" in light of world economic recession. Firstly, one of the central a ks of government policy throughout the 1980's was the genesis of marketisation iv the public so 1 . Government reforms in education and the health service, for example onstry a quasi-market with internal commissioning and provider roles to stimulate the 'ing' a d 'selling' of in-house services (Means and Smith 1997). Simult ysly, h legi ation required local authorities to embark upon a phased programme, dete mine py centry sovernment, through which many of its services had to be subjected to con so so strategy of decreasing the role of local authorities and sth Tating instead the private sector.

The which underpins all of these policy initiatives is a belief that a competitive market and a 'mixed economy of welfare' will inevitably provide better, cheaper services than a protected and bureaucratised public sector (Means and Smith 1997). This policy essentially channelled public sector funds into the private institutional sector while leaving the domiciliary sector chronically under-resourced and led to a 'perverse incentive' that undermined the commitment to community-based care. Private residential homes flourished and in the absence of community services, older people as 'consumers' had little 'choice' other than the decision about which institution they might enter in the 'residential private sector plc'. 
Community care has been used as a vehicle for the marketisation of the public sector. Thus, a 'contract culture' was to be applied to the provision of personal social services and social services departments would need to develop processes to specify, commission and monitor services delivered by other agencies. The organisation of service delivery was to be instigated through assessment and care management including devolved budgets and decentralisation (Powell 2010).

Care managers were seen as central in this process. Yet the political issues for care managers to implement community care policy has not focused at all on managing users groups with leaderships sensitised to diversity. Worse, is that the trust process has become in molicypractice-theory matrix so broken it requires a novel way of theorizing trust o help d professionals and users to each other to help leadership and communication flo sh otherm a fragmented community care system will further fragment the broken relat betwe managers and users in the UK. Managing diversity requires diverse unde standing o iffer.nt levels of trust.

\section{NAVIGATING TRUST IN CARE MANAGEMENT}

\section{1. Individuals, Organisations, Community and Syst}

The first key focus for theorising trust has peen the interpey,onal qualities of the individuals involved. Sztompka (1999) challenges t orists who fonsider interpersonal forms of trust as the primary form based on face-to-face counters y hile subordinating all other forms of trust, collectively referred to as social trust. on any differentiation between interpersonal trust and social forms of trust anoses that the ever-increasing impersonal nature of relationships in systems is underpi ned oxperiences of trust in face-to-face relations between care managers and users. $T$ reliance on the interpersonal aspect of trust suffers from similar problems to Ciaa (1990) 'se of 'ontological security', a product of early childhood experiences, as rerec isite for individuals being able to form trusting relationships. This consery se those without positive childhood experiences stuck in a psychoanaly c mire th no potential for trusting, or by implication being trustworthy, while alo ta $\mathrm{g}$ to offer ny means of recovery. A number of theorists (Davies 1999, Giddens 1901, Mech 1998) note the expectations lay people have of experts or professionals y'lle at the san this interpersonal level provides the human aspect or 'facework' $f$ more 'mpersonal forms of trust. Expectations of professionals include the following: spe compet ycies, specialised areas of knowledge and skills, disinterestedness and dis ure. artic ar importance are communication skills and the ability to present com lex in ormatio, longside, run role expectations that demand experts act ethically and wh teg the true agents of their clients, requiring them to put personal beliefs and interests aside a gcting wo maximise benefit and to do no harm. Creating specialized spaces reinforced by fiduci. norms arising from: the custody and discretion over property, the opportunity and possession of expertise and the access to information; regulates the power/knowledge relationship between expertise and laypersons (Giddens 1991, Shapiro 1987).

The second level of trust is at community level. Evidence exists of a positive correlation between levels of interpersonal trust and levels of social capital (Putman 1993, Rothstein 2000), leading in part to calls for increasing the levels of civility and community responsibility in everyday life. However, while theorists (Misztal 1996, Putman 1993, Taylor-Gooby 1999, 2000, Sztompka 1999, Rothstein 2000, Dean 2003) support the idea of social norms and values overriding rational models of human behaviour, they say little about how these norms and 
values become established. Rothstein claims that the link between interpersonal trust and social capital is weak, as are propositions about the direction of community relationships in managing diversity - care managers are bound up in this process. Rejecting functionalist explanations linking norms to the established configurations of power, he proposes a theory of 'collective memories' creating social norms in communities as a strategic political process. The essential ingredient is the creation of conditions of community relationships built on common values and aims of both care managers and users in communities.

The third key issue is on trust and organisational context. Challenges to the 'trustworthiness' in organisations, regardless of whether they are public or third-aector organisations, can have profound effects on confidence in that system. Produci $\mathrm{g}$ incr $\mathrm{d}$ demands for regulation, information and transparency; that is, increasing th demands distrust. Community care organisations are central to this and need to facilitato st so th interactions with users are transparent and trust facilitated.

The fourth major area of concern for theorising trust has focuss on thecling trust in both state mediated social systems such health and social care an the cssions nibedded therein (Davies 1999, Phillipson, 1998, Welsh and Pringle 2001/Conceiv as im personal or systems trust (Giddens 1990, 1991, Luhmann 1979) this or of trust is eveloped and maintained by embedding expertise in systems that do not quire persoral knowledge of any individual by another. Such systems employ a ra on techniq of distrust i.e. audit processes, target setting and third party inspections filbert 1998, 200\%) which could alienate professionals and users.

\section{2. Implications of Trust in Community Care}

Part of the confusion concerning the dit erch of trust rests, according to Möllering (2001), with the failure to distinguish betw er the anctional properties of trust and the foundations of how trust is created mmunit care. The former are the outcomes of trust i.e. expectations, concerning issue such order, -operation, reducing complexity and social capital. While the latter conoern $n$ ases of trust, which, due to the assumption that they are rational, become ost and th fore not explored. Moreover, individuals make decisions on partial knowledge, ? of weak in kive knowledge and faith regarding the consequences of an action. Mölleri sug ts that in some circumstances relational aspects producing either confidence or rec pucity mig upport decision-making. However, this knowledge moves us close to config ence, hich acco ang to Seligman's (1997) is a different quality. Nevertheless,

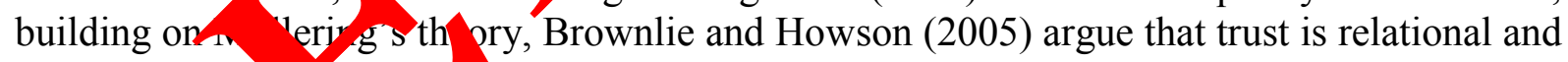
impossible to us rstand $\mathrm{A}$ isolation. Trust occurs as individuals extract the known factors while oro ting o or suspending the unknown factors to avoid confusing decisions with un taint take takes up this relational aspect of trust and claims that relationship issues provide main challenges for community care practices and services. Making the link between sy $\mathrm{cms}$ and social capital, she compares UK and US health care systems. Concluding that the general acceptance by the UK population of the altruistic element of the UK health system stands in stark contrast with the distrust, which accompanies health care in the USA where there is a belief that the system is organised to maximize the benefits for the medical profession. Gilson argues that trust involves both cognitive and affective elements.

The former relates to a risk calculation where the costs and benefits of an action are calculated alongside of the degree of uncertainty derived from the dependency on the actions and intentions of another while the latter is linked to the generation of emotional bonds and obligations. Altruism provides a special case of trust where trusting and trustworthiness 
promote the social status of those involved in giving thus enhancing trust relations between care managers and users.

Other writers draw distinctions between trust and hope. Both Sztompka (1999) and Gilbert $(1998,2005)$ discuss trust and hope, with hope representing a situation of relative powerlessness, a situation exemplified by Gilbert who concludes that trust is a discourse of professionals and experts while hope is a user discourse. Seligman argues that trust, conceived as it is in this debate, is unique to modernity. In traditional societies, trust has quite different bases. Moreover, sociological theories, which suppose a general change in modernity (cf. Beck, 1992, Giddens 1994), assume that with the erosion of traditional institutions and caintific knowledge trust becomes an issue more often produced actively by indi iduals in institutionally guaranteed. To resolve these tensions we propose Foucault's $C$ ernmentar thesis as the means to identify the role of trust, along with the mechanisms for th ployme of trust and the role of professional expertise. Social institutions suct as comm ty are disseminate a particular ethic of the self into the discrete corners $g$ every population. Supported by a discursive framework promoting co-c era elation between people, communities and organisations this ethic is future orienta ed and pro tes alities and values that sustain trust-based relationships and forms of acti $n$. the proces 1 building cooperative relations, the role of professionals and professiona gutho is established. The next section carefully examines the conceptual possibiun for ar lokion of trust and governmentality.

\section{3. Linking Care Management with Trust and $G$ arnment ity}

Conceptually there are tensions but an interesting oretical possibilities between late [high] modern and post-structuralist concept ns is iety. Both identify the fragmentation of traditional forms of authority and expertise, a d ackn, vledge the increasing complexity this produces through the availability ultiple ources of information and different lifestyle choices. As noted earlier late $[\mathrm{b}, \mathrm{h}] \mathrm{m}$ ern con stions of trust, acknowledge uncertainty and risk as the basis for necessivith tru fur the failure of rational choice theories as evidence of the existence of sucia st. Likewise, governmentality theorists, discuss risk and uncertainty at length (P 1996, 199, oborne 1997, Petersen 1997), but leave the discussion of [social] 'trust' to obsu tion that trust, traditionally placed in authority figures, has been replaced by aud Rose 19, The problem of creating co-operative relations between individuals an with groups a communities, both in the present and for the future, is left unresolved saur s sur mary of the working of the state provides a useful starting point for this discussion:

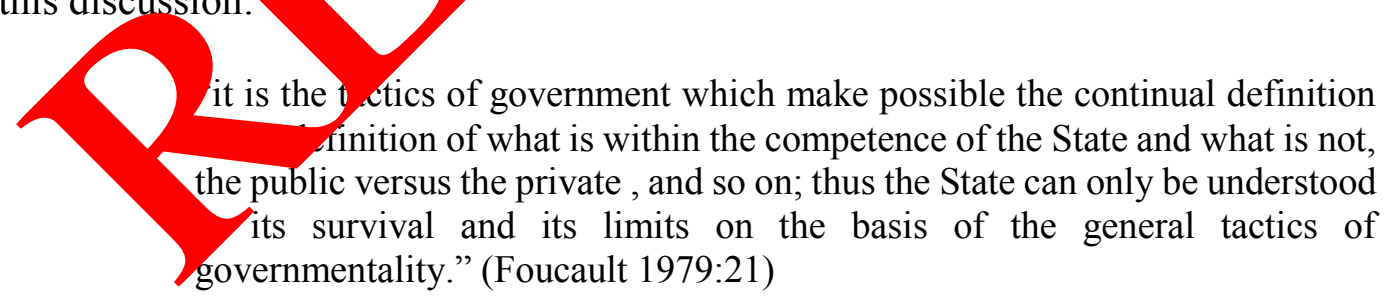

Our contention is that the 'governmentality thesis' as it has been developed by writers such as: Rose and Miller (1992), Burchell (1991), Rose (1996, 1999), Osborne (1997), Petersen (1997) holds the potential to overcome many of the problems experienced in theorising trust. It provides a means of extending the critical debate over trust. Linking discussions concerning the bases of trust: the conditions Möllering (2001) describes as essential for trust to happen with discussions focusing on the outcomes of trust i.e. social capital, systems or impersonal trust and 
interpersonal trust (Putnam 1993, Seligman 1997, Luhmann 1979, Giddens 1990, 1991, Sztompka 1999, Rothstein 2000).

Moreover, governmentality provides the means for identifying the mechanisms for deploying particular rationalities across the social fabric. In particular, the interplay between state intervention and the population that institutionalizes expertise as a conduit for the exercise of power in modern societies (Johnson 2001). Institutionalizing expertise establishes a range of specialized spaces: at once both hidden and visible, providing opportunities across the social landscape for a range of care managers. Experts who work on individuals inciting self-forming activity and individual agency, producing the self-managing citizen central to neo-liberolforms of government, 'enterprising subjects' or what Burchell (1991: 276) terms 'respor sibilisa Thus enabling an explanation of trust that avoids resorting to a functionalist ument or overly deterministic approach limited to either class action or the meaning-g o subje Furthermore, governmentality can overcome the condition laid by Szton pka (1999, at ty ast cannot exist in conditions of discontinuous change. Indeed, in the a text $d$ discon auous change, particular rationalities and their associated technologies be mo acized, ading to increased conflict in the relationship between the state and exper se makin. ust a, ever more valuable commodity.

In analysing the activities of government, Rose and iller $\quad 02: 175 \%$ argue, we must investigate 'political rationalities' and technologies of ove ment - a smplex of mundane programmes, calculations, techniques, apparatuses, $q$ scuments and prodedures through which authorities seek to embody and give effect to governn ntal ambitio $1 s^{\prime}$. In this case, rationalities, operating as discourses and social practices embod, a partic alar practical ethic, work to reproduce the norms, values and obligationsassociated st. Producing a subject position that values trustworthiness as both a personal and a chacteristic sought in others. Both experts/professionals and the user/cus om sealth services emerge as the selfmanaging ethical subjects of neo-liberal rule (1 1ler 1993, Davidson 1994, Rose 1999).

For governmentality theor sts a malysis neo-liberal regimes reveals individuals as inculcated with values and obs ves, rientated cowards incorporating people as both players and partners in marketised social care. Participation in markets along with the potential unbound hoice are inextricably entwined with a creative tension, an ethical incomplete ess, ere privat _selfish] desire and public [selfless] obligation produce the rational self-m najo a ding neo-liberal rule. In a dialectical relationship that works to form individua identity throus the exercise of a modern consumerist citizenship (Miller 1993). Such oimes hort individuals; indeed expect them to become entrepreneurs in all spheres, and to ept res nsibility for the management of 'risk'. Government is concerned with m ing the ndu $/$ of conduct, the processes through which people 'govern' themselves, whi n inc les an os sation to manage one's own health (Petersen 1997).

The nodornity such as Putman (1993), Sztompka (1999) and Rothstein (2000) leave to arise organically through the interaction of individuals within groups and communt The idea that increasing the levels of social interaction to effect a positive consequence on the levels of social and individual trust has a benign attraction, but it tells us little about how or why these norms, values and obligations associated with trust exist in the first place. Alternatively, the analysis of governmentality recognizes these discourses and social practices as the outcome of something more ordered. Not ordered in the sense of designed and managed but the consequence of what Foucault described as strategy: loosely connected sets of discourses and practices that follow a broad trajectory with no necessary correspondence between the different elements (Dreyfus and Rabinow 1982). 
One tactic, increasingly used within the strategy of government as they struggle with the challenge of managing populations across an ever more complex range of social contexts, is the promotion of co-operative relations within different programmes and technologies. This works to promote, establish and maintain an ethic of co-operation and trustworthiness producing the trusting subject as a version of the disciplined subject, socially valued and malleable. Evidence of this can be found in a range of policy initiatives disseminated by national and local government drawing on communitarian discourses and including an endless array of devices promoting partnerships and active citizenship e.g. Caring about Carers (DoH 1999), Choosing Health (DoH 2004), Independence, Well-being and Choice (DoH 2005). Devices tamating communities and neighbourhoods through initiatives promoting community ac vities in focussed on a variety of locally based independent and autonomous groups. In as where operative relations have failed and require rebuilding the deployment of a vurses empowerment is evident, inciting 'damaged subjects' to self-manage (R se 1996). initiatives such as Health Action Zones, Community Development Pr scts an Public realth activities a range of experts and lay volunteers work on individual en ging th to take responsibility for their health and engage in self-forming activitie self-car self nelp (Rose 1999).

Alongside this promotion of co-operative relations $\mathrm{ss}$, no iberal rale increasingly repositions the state as the co-ordinator of activity rat tor an the podernising Social Services (DoH 1998), Every Child Matters (D H 2003b), Choos ng Health (DoH 2004) and Independence, Well-being and Choice (DoH $2($ 5)], progres ively drawing communities into the provision of welfare and the management ocial pro lems (Clarke and Newman 1997, Rose 1996, 1999). New, often contradictory, operation, of participation and consumerism for earlier forms of public provision. Nevertheless, these contradictory rationalities aip an. ficient coherence to provide the basis for state intervention through profescional and y activity.

One such example is the r struc red rela onship between the private health sector and the British National Health Se [N S] (DoH L002, Lewis and Gillam 2003). Until recently, the private health sector di ce nHS arguing quality and choice while those committed to a public lith servio ajected private sector values. Now, a range of policy initiatives such as th us f private ctor surgical facilities, the ability to have particular treatments at a fac ${ }^{\top}{ }^{7}$ ty chose have blurred the ooundaries bet on the public and private health sectors. Fixing large sections of the privat ector he reserve capacity of the NHS expanding and contracting on demand without the po 1 conse lences of public hospital closures. Furthermore, the use of private

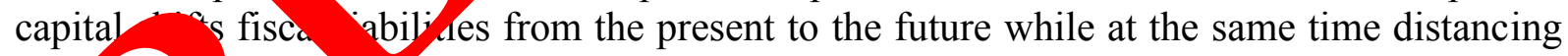
the ate fr $\mathrm{h}$ respon onlity for the maintenance and refurbishment of hospital and other health serv far and equipment.

7 deveropments suggest a re-articulation of the discursive structure of private, voluntary dstatutory sector organisations in what Clarke and Newman (1997) describe as processes of colonisation and accommodation. Alongside State interventions aimed at provoking co-operative and trust-based relationships, such movements point to the way major institutions of society can become repositories of trust, providing both the example and the experience of trusting while also building the capacity for trust-based relationships across the social fabric. However, in contrast to functionalist conceptions of social institutions as repositories of trust e.g. Misztal (1996), we need to identify the dynamic interplay between the state and the means of intervention at its disposal. 
The challenges faced by the state over the last twenty-five years or so such as the increasing health costs of an ageing population (Rose 1999, DoH 2005) have been matched by rapid social change. One effect of this has been the fragmentation of welfare away from a monolithic state organisation to one co-ordinated and financed by the state but disciplined by market mechanisms such as commissioning and competitive tendering (Clarke and Newman 1997, Lewis and Gillam 2003). Another effect has been the politicization of the technical i.e. professional expertise (Johnson 2001), where a variety of forms of expertise competes for dominance. Under such conditions, trust is also politicized (Gilbert 1998). Trust becomes a commodity for exchange (Dasgupta 1988). Demanding new forms of governam and producing a paradox, autonomy for organisations and professionals released irom ct management by the state is matched by ever more-complex forms of surveilla and cont (Rose 1999, Gilbert 2001).

Since the $1980 \mathrm{~s}$, claims of a decline in the authority of the profess ns accomed is process. Public perceptions of failures of professional self-r latio articu as institutionalized self-interest (Davies 2000), paralleled by the incre sin ${ }_{0}$, ver, or sistance, of health service users and welfare consumers to discipline profe sional ac. $\mathrm{v}$. M anagerialist techniques such as contracts and demands for transparency in ex nges uni canagerial and user based discourses in an uncomfortable marriage (Ros 199 , haw 2001, Stewart and Wisniewski 2004, McIvor et al. 2002), frustrating the rom voice or rmovements (Clarke and Newman 1997). Alongside, a massive increase in he access to the iv 1ormation, particularly through the internet, further complicates the situat n. Specialis 1 information, once the sole privilege of the professions, is now widely avail changi,g the relationship between professionals and laypersons once again che1lenging pl al authority (Hardey 2005).

For Rose and Miller: 'govern mentality sically linked to the activities of expertise, whose role is not weaving an all-pervasive eb colal control" but of enacting assorted attempts at the calculated administration of div se aspects of conduct through countless, often competing, local tactics of edcati persuc ion, inducement, management, incitement, motivation and encourageme Rose and Mil or 1992: 175). This web of activity and the specialized spaces created ex sc wuthe to construct professional authority, condensing the different levels of t t: interpe systems and social capital; into the face work of experts. The fragmen atio fexpertise once embedded in the directly managed institutions of the state, has enab ${ }^{\text {th }}$ he dis , al of this expertise throughout the third sector leading to a rearticulation of $y^{1}$ e discourses th

It is no te tha spite the conflicts of the 1980 s, the care managerial professions appear to carry on rela y unsca ed leading to the conclusion that the decline in the authority, power and po rity or pro essions has been overstated. One key factor is that certain tasks and

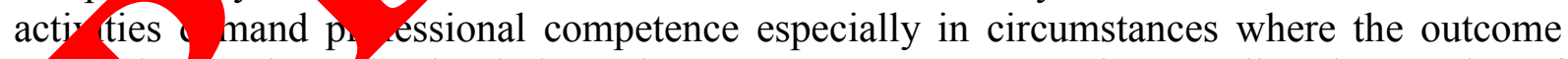
cam be doter hined (Clarke and Newman 1997). Once again, revealing the paradox of autono and increasing regulation in the relationship between the state and professional activity. nuing to the earlier quotation from Foucault, what has occurred in this period is the re-articalation of government objectives and a re-structuring of the realms of professional jurisdiction and authority (Johnson 2001). Regulation and control of expertise through audits and contracts are disciplinary techniques that have modernized the tricky issue of governing professional activity. Accompanied by a re-articulation of professional discourse objectifying the activity of expertise rendering it both manageable (Rose 1999), and enabling the surveillance of professional activity across a landscape no longer defined by institutions and buildings of the poor law. At the same time policy documents such as 'Choosing Health' (DoH 
2004) and Independence, Well-being and Choice (DoH 2005) are unashamedly consumerist, demonstrating shifts in the way community care is managed.

Central to this process is a paradox where the need for experts to manage complex and unpredictable situations has led to trust in professional autonomy becoming almost exclusively located with the management of risk (Rose 1996, 1999, Petersen 1997, Kemshall 2002). Competence in the management of risk is therefore the central basis, which maintains the professional status of health and social care professionals. Failure in this respect can lead to very public examinations of the competence of individual professionals, in particular where there is danger of a legitimation crisis. Professionals who, despite evidence of system failure, experience a form of symbolic sacrifice and public humiliation, recent example incluc $\mathrm{Dr}$ Marietta Higgs [Cleveland Child Abuse Inquiry], Lisa Arthurworrey [Victoria $/$ vbie's soo worker] (James 2005) and Professor Sir Roy Meadows [expert witness ip chil ath cas (Laville 2005)].

Challenges to traditional or institutionalized expertise by new or n-con ntiona orms of expertise also demonstrates this re-structuring of the objectiy a ernme and the jurisdiction of professionals. Some problems have persistently ustrated ition al forms of expertise in health care and social welfare at the same time wi s. contract based activity enables entry for alternative approaches. Here ara the amic quality of Govern mentality, demonstrates processes of colonisation and accummodat Jee-Treweek (2002) explores this process in the context of a complementa $y$ therapy, crania) osteopathy, describing how traditional medicine accepts elements of com ementary prictice on condition that the alternative approach accepts particular rituals and the nacy of th existing medical hierarchy. The need to manage chronic conditions such as sko a muscular pain, areas where traditional medicine has failed to provide a $n$ treatment, enables a new form of expertise to institutionalise itself with the state. Securin tru sus specialized space enables this form of expertise to contest the hegemonv af risk to s advantage.

\section{CONCLUSIONS}

This article has eve the em gence and consolidation of community care policy in the UK and impr $n$ rela $s$ between care managers and user groups underpinned by diversity. One $\mathrm{o}$ the central pro ins of facilitating any leadership or rapport for care managers with older $r$ ple in $\mathrm{g}$ UK has been the issue of 'trust'. As we have seen, where is a multiplicity of that tr thas been defined but the central paradox is how to creation of the conditi of but o conditions of trust across personal-organisational-structural tiers in an incr asing uncerta world. The chapter has assessed community care policy and navigated the rs capture stronger bonds and relationships between care managers and us roups such as older people in the UK. This is an immense conceptual and experiential challenge. hat emerges is a fusion of consumerist, traditional, alternative and complementary discourses 2 rticulated with discourses of co-operation, partnership and trust in health and social care providing an matrix of spaces where a wider range of expertise, in both type and numerically, than ever before is embedded. At one level, experts identify risk at the same time as providing a general surveillance of the population, at another level they work within systems legitimated by a myriad of mechanisms of distrust while simultaneously working at another level on individuals to promote a general ethic of trust. Thus, the mechanisms constructing the contemporary authority of expertise are established. Managing diversity is inextricably linked to trust. Condensing trust in the face work of care managers places users of health and social 
care in a dynamic context. Community care policy continually redefines previous patterns of social relationships both within health and welfare agencies and between those agencies and their customers. Gilbert et al. (2003) identified professionals in health and social care agencies responding to policy pressures by managing the expectations [trust] of different individuals and groups with potentially conflicting interest's e.g. individual users, parents/carers and the local community. These experts engaged in a process of change and consolidation managing conflict while furthering both organisational and political aims related to community care. Hence, this process is needed to be further sustained to have a better understanding of how users and care managers can actually understand, listen and respect each other.

\section{BIOGRAPHY}

Professor Jason L. Powell BA (Hons), MA, Ph.D, FRSA is Professor of Social Gero cology d Asso dean of Faculty of Health and Life Sciences at University of Coventry. He holds an Hon Felle wsip U, Aversity of Liverpool; Honorary Professor at Australia-Asia Research and Education Fo atio Tasmani Jniversity; Visiting Research Fellow at Oxford; and recently invited as Visiting Scholar tharvard he has been Visiting Professor in Canada, US, Australia, Africa and Jordan. He was $y$ ol ted and ele .0 Fellowship of the British Royal Society of Arts (FRSA) in recognition of his research He hâ ong interests in social theory, ageing, power and identity. He is author of Social Theory and Agein 2006) whic is part of Charles Lemert's distinguished 'New Social Formations' book series, Rowman an' Littletield: New Yy

\section{References}

[1] Age Concern England (1997). Age Matt 's. . London.

[2] Allen C. (et al.) (1994). Socio in a Mr ed Economy, Open University Press, Milton Keynes.

[3] Allen I. (et al.) (1992) cherl) ople. croice, Participation and Satisfaction, Policy Studies Institute,

[4] Audit Commissi (19, Making a Reality of Community Care, PSI, London.

[5] Audit Com nission (1996). Mancing the Care Equation: Progress with Community Care, HMSO

[6] Biggs S. (1) Unde standing Ageing, OUP, Milton Keynes.

[7] oiggs , Poweh, Journal of Contemporary Health 4(1) (2000) 41-49.

[8] a P. (1990). Ageing in Society, Sage, London.

[9] Bono (1996). Trends in Dependency Among Older People in England, OPCS, London.

[10] Bornat J. (Eds.) (et al.) (1993). Community Care: A Reader, OUP, Milton Keynes.

[11] Bornat J. (Ed.) (1994). Reminiscence Reviewed, OUP, Milton Keynes.

[12] Bowl R. (1986). 'Social work with old people' in Phillipson, C and Walker, A (1986) Ageing and Social Policy, Gower, London.

[13] Chau W. F., Accounting Organisations and Society 20(2) (1995) 111-145. 
[14] Clarke J. (1994). 'Capturing the Customer: Consumerism and Social Welfare', paper to ESRC seminar Conceptualising Consumption Issues, Dec.1994, University of Lancaster.

[15] Deakin N., Social Policy and Administration 30(1) (1996) 20-38.

[16] Department of Health (1989). Caring for People: Community Care in the Next Decade and Beyond, Cm849, HMSO, London.

[17] DoH (1991). Caring for People: Implementation Documents, Draft Guidance: Assessment and Care Management, HMSO, London.

[18] DoH (1994). Community Care Packages for Older People, HMSO, London.

[19] Du Gay P. (1996). Consumption and Identity, Sage, London.

[20] Fennell G. (et al.) (1988). Sociology of Age, OUP, Buckingham.

[21] Finch J. (1986). 'Age' in Burgess, R (Ed.) Key Variables in Socio "nvesty London.

[22] Flynn R. (1992). Structures of Control in Health Manage nt, Routle vondon.

[23] Fowler N. (1984). 'Speech to Joint Social Services An. al Co rence', 27/9/84, DHSS, London.

[24] Gabe J. (1991). The Sociology of the Health Se ice, Routledge, London.

[25] Griffiths Sir R. (1988). Community Care: Agen for Action HMSO, London.

[26] Henwood M. (1990). Community Car and Elder,y Policy, Practice and Research Review, Family Policy Studic

[27] Henwood M. (1995). Making a Differend ?, Nuffjeld Institute for Health/Kings Fund Centre, London.

[28] Hills J. (1993). The Futh $W_{e}$ care a gonde to the debate, Joseph Rowntree Foundation, York.

[29] Hockey J., James 1993). Gro G Up and Growing Old: Ageing and Dependency in the Life Cours Sage, ndon.

[30] Hospital avisary Servicu 982). The Rising Tide: Developing Services for Mental Illness dold re, HMSO, London.

[31] Hughes B. 95). O ler People and Community Care: Critical Theory and Practice,

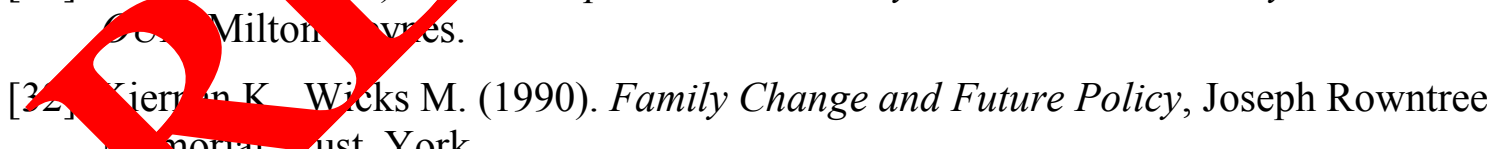
norrar must, York.

[33] Leviy \%., Critical Social Policy 34 (1992) 76-81.

[34] Lewis J., Glennerster H. (1996). Implementing The New Community Care, OUP, Milton Keynes.

[35] Meredith B. (1994). The Next Steps: Lessons for the future of community care, ACE, London.

[36] Phillipson C. (1982). Capitalism and the Construction of Old Age, Macmillan, London. 
[37] Phillipson C. (1988). 'Challenging Dependency: Towards a new Social Work with Older People' in Langan, M and Lee, P (Eds.) (1988). Radical Social Work Today, Unwin Hyman.

[38] Phillipson C., Walker A. (Eds.) (1986). Ageing and Social Policy: A Critical Assessment, Gower, Aldershot.

[39] Qureshi H., Walker A. (1989). The Caring Relationship, Macmillan, London.

[40] Seebohm Committee (1968). Report of the Committee on Local Authority and Allied Personal Social Services, Cmnd 3703, HMSO, London.

[41] Smart B. (1985). Michel Foucault, Routledge, London.

[42] Vincent J. (1996). Inequality and Old Age, University College Londor Press, ondon.

[43] Walker A. (1985). The Care Gap, Local Government Information servic Lona

[44] Walker A. (1993). 'Community Care Policy: From Consensu 00 a ct' in B nat, $J$ (et al.) (Eds.) Community Care: A Reader, O.U.P.

[45] Walsh K. (1995). Public Services and Market Mechan ms, cmillan, yndon.

[46] Wardhaugh J. ,Wilding P., Critical Social Policy 2-193) 4-3

[47] Arnes A. (Ed.) (1996). Human Ageing and Lat Life, Edward Arnold, London.

[48] Webb A., Wistow G. (1987). Social Work, Soc Care and ocial planning: The Personal Social Services Since Seebohm, Longm

[49] Williams F. (1994). Social Policy: A C, thoduction, 2nd Edition, Blackwell, Oxford.

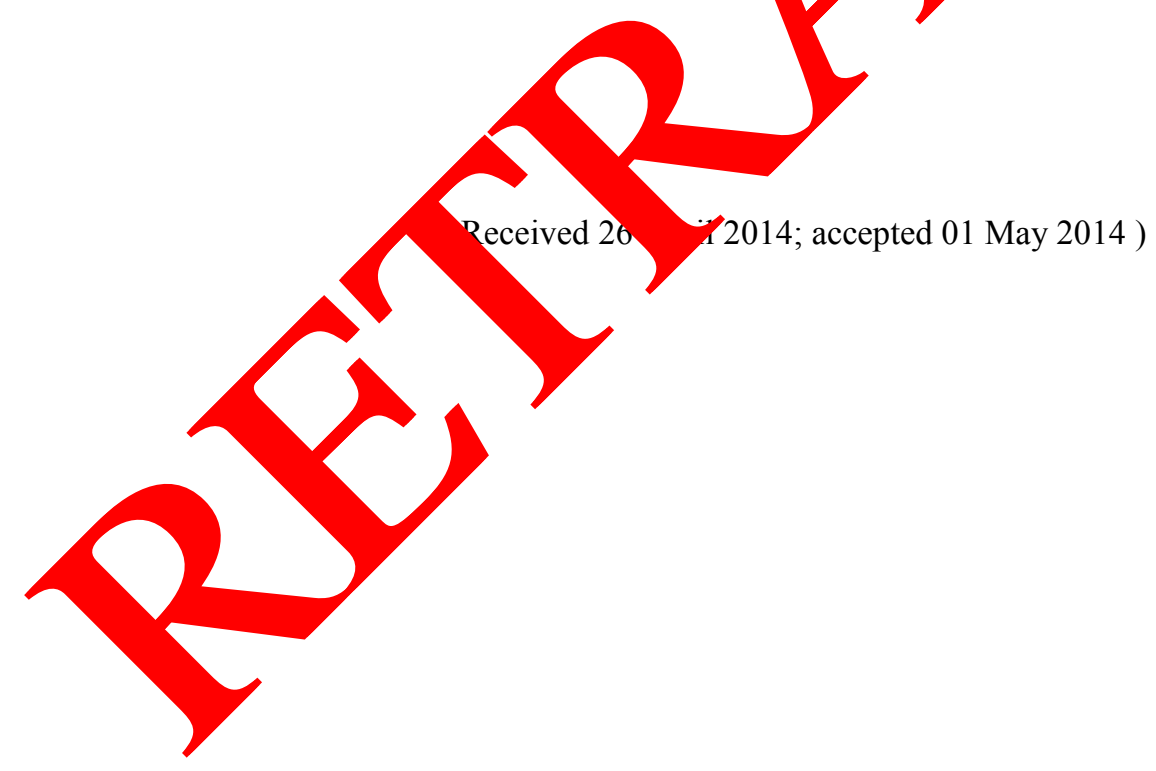

